\title{
Rapid Residue Analysis of Sulfonylurea Herbicides in Surface Water: Methodology and Residue Findings in eastern Tiaoxi River of China
}

\author{
Ninghui Song, Min Guo, Yang Liu, Lili Shi \\ Nanjing Institute of Environment Sciences, Ministry of Environment Protection, Nanjing, China \\ Email: snh@nies.org
}

Received 5 May 2016; accepted 16 June 2016; published 21 June 2016

\begin{abstract}
A new method combining QuEChERS (quick, easy, cheap, effective, rugged and safe) and DLLME (dispersive liquid-liquid microextraction) for the simultaneous determination of residues of ten sulfonylurea herbicide in water using UPLC-MS/MS was developed and validated. Analytes were extracted and purified with QuEChERS and concentrated in chlorobenzene by applying the DLLME procedure. Several extraction parameters were tested, such as volume, extractive solvent by the QuEChERS method and subsequently used for DLLME, selection of extractive solvent and its volume, was tested. The developed method was validated on the basis of international guidelines. Mean recoveries ranged from 81.2 to $104.9 \%$. Repeatability and reproducibility were lower than $10 \%$. Limits of detection (LODs) and quantification (LOQs) were below $0.074 \mu \mathrm{g} / \mathrm{L}$ and $0.244 \mu \mathrm{g} / \mathrm{L}$, respectively. Decision limit (CC $\alpha$ ) and detection capability (CC $\beta$ ) were calculated and CC $\beta$ ranged from $0.101 \mu \mathrm{g} / \mathrm{L}$ (pyrazosulfuron-ethyl) to $0.260 \mu \mathrm{g} / \mathrm{L}$ (nicosulfuron). Finally, when the method was applied to real samples, traces of three compounds were found in 42 samples and only thifensulfuon-methyl was detected above the LOQ in three samples at $0.17(0.20 \mu \mathrm{g} / \mathrm{L}$.
\end{abstract}

\section{Keywords}

Sulfonylurea herbicides, pesticide residues, UPLC-MS/MS, QUEChERS, DLLME

\section{Introduction}

Sulfonylurea herbicide, composed of a sulfonyl structure linked to a urea group, is among one of the largest classes of herbicides [1]. Sulfonylurea herbicide is extremely toxic to a wide spectrum of weeds requiring relatively low application rates with typically less than $100 \mathrm{~g}$ of active ingredients per hectare for effectivenes [2]. Relatively high water solubility combined with low log Kow indicates possible leaching of this herbicide to a deeper soil layer, potentially allowing entrance to surface waters via drainage systems [3] [4]. The herbicidal mode of action is very specific acting to inhibit the enzyme acetolactate synthase and sensitivity to these herbicides at relatively low levels $(\mu \mathrm{g} / \mathrm{L})[3]$ is exceptional among certain specific water plants (e.g. duckweed, 
Lemna minor). Monitoring residues in surface waters at trace levels is of great importance to quantify contamination to aquatic weeds.

Detection and analysis of sulfonylurea herbicide is more difficult compared to that of traditional herbicides due low rates of use. So, new and reliable analytical methods including sample preparation and preconcentration procedures, a vital step of the analytical method, are necessary to develop and obtain trace analysis. Currently, a series of conventional methods such as the traditional liquid-liquid extraction (LLE) [5], solid phase extraction (SPE) [6] [7], immunoaffinity (IA) [8] and continuous flow liquid membrane extraction (CFLME) [9] are utilized to pre-treat sulfonylurea herbicide residue in surface water. Each of these methods, though effective, experience challenges dealing with time consumption, solvent consumption, or expensive. Conventional methods also cannot detect trace or very low amounts of sulfonylurea herbicides in environments [10]. Recently, QuEChERS sample preparation has been introduced and applied worldwide in many studies for pesticide residue analysis in different matrix samples [11]-[14]. Flexibility and a high degree of selectivity and sensitivity characterize the QuEChERS procedure [15]. A major disadvantage is experienced as a result of its low enrichment factor, however [16]. Extraction and concentration of compounds is also performed utilizing a recent technique referred to as dispersive liquid-liquid microextraction (DLLME) [17]. DLLME is a miniaturized liquid-liquid extraction (LLE) that uses microliter volumes of the extraction solvent [18]. Advantages of DLLME include requirements for use of only a small volume of organic solvents, simple operation, rapidity, low cost, high enrichment factor and simple linkage capability to analytical methods [1] [19]. Sample preparation procedures were combined to improve the enrichment factor, leading not only to a higher enrichment factor, but also, due to including purification steps in QuEChERS, the ability for use in complex matrices such as severe water pollution samples. Additionally, combining procedures also acts as a time-saving tool as the column tube plug, the most widely used SPE, functions as an alternative to bulk samples. Low limits of quantification using short analysis time then are quantified further by UPLC/MS/MS.

In continuation to our previous endeavors in the exploration of novel sample pretreatment techniques, the aim of this work was to combine the QuEChERS with DLLME in the sample preparation, thus to enhance the selectivity of the DLLME and to extend its application to more complex matrix samples. In this work, the applicability of the combination of QuEChERS with DLLME for the extraction of some sulfonylurea herbicides in water samples prior to their analysis by UPLC/MS/MS was explored, Additionally, surface water assessment of sulfonylurea herbicide residue occurrence in eastern Tiaoxi River of China was further applied to validate the procedure As a result, the selectivity of the analysis was much improved and satisfactory analytical results were achieved.

\section{Materials and Methods}

\subsection{Chemicals and Reagents}

Certificated analytical standards of 10 sulfonylurea herbicides: nicosulfuron (NS; purity, 93.5\%), thifensulfuonmethyl (TFM, 96.7\%), metsulfuron-methyl (MSM, 99\%), sulfometureon methyl (SMM, 99\%), chlorsulfuron (CS, 99\%), ethametsulfuron-methyl (EMM, 99\%), tribenuron-methyl (TBM, 99\%), bensulfuron-methyl (BSM, 97.5\%), pyrazosulfuron-ethyl (PSE, 98.2\%), chlorimuron-ethyl (CME, 97\%) were obtained from Sigma- Aldrich (Steinheim, Germany). Acetonitrile (HPLC-grade) was purchased from Merck (Darmstadt, Germany). Formic acid was supplied from Sigma Aldrich (Steinheim, Germany). Chloroform $\left(\mathrm{CHCl}_{3}\right)$, dichloromethane $\left(\mathrm{CH}_{2} \mathrm{Cl}_{2}\right)$, Carbon disulfide $\left(\mathrm{CS}_{2}\right)$ and chlorobenzene $\left(\mathrm{C}_{6} \mathrm{H}_{5} \mathrm{Cl}\right)$ were purchased from Beijing Chemical Reagents Company (Beijing, China). Anhydrous $\mathrm{MgSO} 4$ and $\mathrm{NaCl}$ were obtained from Wako (Osaka, Japan). Primary secondary amine (PSA) sorbent was obtained from Varian (Harbor City, CA, USA). Ultrapure water was prepared using a Millipore Milli-Q purification system (Millipore Corp., Bedford, MA, USA).

\subsection{Instrumental and Chromatographic Conditions}

Chromatographic separation was achieved for ten pesticides by utilizing a liquid chromatograph equipped with a Waters Acquity UPLC (Waters, USA) BEH C18 column $(50 \mathrm{~mm} \times 2.1 \mathrm{~mm}, 1.7 \mu \mathrm{m})$. The mobile phase consisted of $0.1 \%$ formic acid in water (A) and acetonitrile (B). Elution was performed in the gradient mode (Gradient B; $20 \%$ at $0.1 \mathrm{~min}, 70 \%$ at $5 \mathrm{~min}, 100 \%$ at $7 \mathrm{~min}, 100 \%$ at $8 \mathrm{~min}, 20 \%$ at $8.1 \mathrm{~min}$.). The flow rate was 0.3 $\mathrm{mL} \cdot \mathrm{min}^{-1}$ and injection volume was $1 \mu \mathrm{L}$. The column and autosampler were maintained at a temperature of 45 and $4^{\circ} \mathrm{C}$, respectively. 
The Waters Quattro micro triple quadrupole mass spectrometer (Waters, USA), equipped with electrospray source, was utilized for all experiments; while MassLynx software (version 4.1) was applied in instrument control and data acquisition. The capillary voltage and extractor voltage were set at $3.0 \mathrm{KV}$ and $3.00 \mathrm{~V}$, respectively and source temperature and desolvation temperature were held at $140^{\circ} \mathrm{C}$ and $400^{\circ} \mathrm{C}$, respectively. Nitrogen was used for the cone and desolvation gas flows set at 50 and $800 \mathrm{~L} / \mathrm{h}$, respectively, while argon was used as collision gas at a pressure of $0.1 \mathrm{MPa}$ and flows $0.26 \mathrm{~mL} / \mathrm{min}$. The multiple reaction monitoring (MRM) positive electro spray ion (ESI) mode was operated for each pesticide with all parameters for MRM transitions, cone voltage and collision energy optimised to obtain highest sensitivity and resolution (Table 1). Under this condition, the results showed a symmetrical peak shape and reached the baseline separation with the peak content of other chemicals (Figure 6).

\subsection{Source of Samples}

Water samples were obtained from the eastern Tiaoxi River of Hangzhou city, China on May 2011. Tiaoxi River originates from Linan, feeds into Taihu Lake, and is approximately $151.40 \mathrm{~km}$ in length with a catchment area of $2265 \mathrm{~km}^{2}$. Seven sampling sites along the river were selected based on pollution hotspots, such as the river's entrance, areas near villages, or areas slightly affected by human activities (Figure 1). Pesticide-free water was used as blank matrix to study the methodology.

Table 1. Experimental parameters (herbicide name, pKa, molecular formula, and weight) and UPLC-MS/MS conditions of the herbicides.

\begin{tabular}{|c|c|c|c|c|c|c|c|}
\hline Herbicides & Molecular formula & $\mathrm{pKa}$ & $\begin{array}{c}\text { Molecular } \\
\text { weight }\end{array}$ & $\mathrm{CV}(\mathrm{V})$ & $\begin{array}{l}\text { Quantication } \\
\text { iron ransition }\end{array}$ & $\begin{array}{l}\text { Confirmatory } \\
\text { ion transition }\end{array}$ & $\mathrm{CE}(\mathrm{eV})$ \\
\hline$\underline{\text { NS }}$ & $\mathrm{C}_{15} \mathrm{H}_{18} \mathrm{~N}_{6} \mathrm{O}_{6} \mathrm{~S}$ & 4.8 & 410.41 & 14 & $411.0>182.0$ & $411.0>140.5$ & 20 \\
\hline TFM & $\mathrm{C}_{12} \mathrm{H}_{14} \mathrm{~N}_{4} \mathrm{O}_{7} \mathrm{~S}_{2}$ & 4.4 & 387.39 & 20 & $387.9>166.9$ & $387.9>140.5$ & 16 \\
\hline MSM & $\mathrm{C}_{14} \mathrm{H}_{15} \mathrm{~N}_{5} \mathrm{O}_{6} \mathrm{~S}$ & 3.7 & 381.36 & 20 & $381.9>166.8$ & $381.9>166.3$ & 18 \\
\hline SMM & $\mathrm{C}_{15} \mathrm{H}_{16} \mathrm{~N}_{4} \mathrm{O}_{5} \mathrm{~S}$ & 5.2 & 364.38 & 25 & $364.9>150.1$ & $364.9>198.6$ & 18 \\
\hline CS & $\mathrm{C}_{12} \mathrm{H}_{12} \mathrm{ClN}_{5} \mathrm{O}_{4} \mathrm{~S}$ & 3.4 & 357.77 & 20 & $357.9>166.8$ & $357.9>140.7$ & 16 \\
\hline EMM & $\mathrm{C}_{15} \mathrm{H}_{18} \mathrm{~N}_{6} \mathrm{O}_{6} \mathrm{~S}$ & 4.6 & 410.41 & 20 & $410.9>195.7$ & $410.9>169.8$ & 16 \\
\hline TBM & $\mathrm{C}_{15} \mathrm{H}_{17} \mathrm{~N}_{5} \mathrm{O}_{6} \mathrm{~S}$ & 4.7 & 395.4 & 20 & $396.1>199.3$ & $396.1>154.4$ & 15 \\
\hline $\mathrm{BSM}$ & $\mathrm{C}_{16} \mathrm{H}_{18} \mathrm{~N}_{4} \mathrm{O}_{7} \mathrm{~S}$ & 5.2 & 410.4 & 25 & $411.0>181.9$ & $411.0>148.9$ & 22 \\
\hline PSE & $\mathrm{C}_{14} \mathrm{H}_{18} \mathrm{~N}_{6} \mathrm{O}_{7} \mathrm{~S}$ & 3.7 & 414.29 & 25 & $415.0>181.3$ & $415.0>181.8$ & 18 \\
\hline CME & $\mathrm{C}_{15} \mathrm{H}_{15} \mathrm{ClN}_{4} \mathrm{O}_{6} \mathrm{~S}$ & 4.2 & 414.82 & 20 & $415.0>185.9$ & $415.0>212.7$ & 20 \\
\hline
\end{tabular}

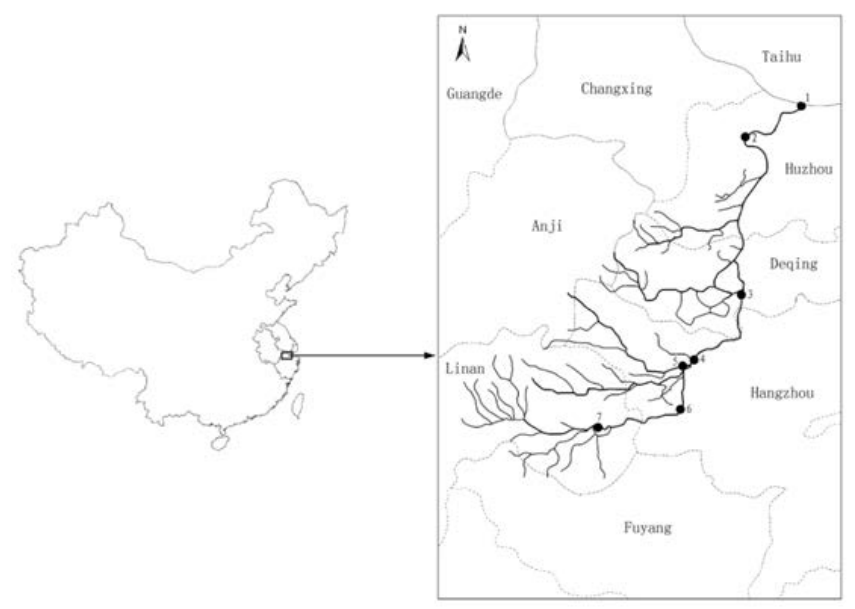

Figure 1. Geographical location of the basin and water sampling stations in the Dongtiaoxi basin. 


\subsection{QuEChERS-DLLME Procedure}

A volume of $10 \mathrm{~mL}$ of each water sample was placed in a $50 \mathrm{~mL}$ centrifuge tube with conical bottom and was then spiked with appropriate volumes of 10 sulfonylurea herbicides standard solutions, waiting $30 \mathrm{~min}$. for equilibration. Formic acid was added to adjust $\mathrm{pH}$ to 3 for the prevention of analytes converting to ionic form. Extraction preparations included: $10 \mathrm{~mL}$ acetonitrile was added to the solution and mixed using a vortex mixer for $1 \mathrm{~min}$, then $4 \mathrm{~g}$ anhydrous $\mathrm{MgSO}_{4}$ and $1 \mathrm{~g} \mathrm{NaCl}$ were added and the solution mixed again for $1 \mathrm{~min}$. The tube was then centrifuged for $5 \mathrm{~min}$ at $6000 \mathrm{r} / \mathrm{min}$. $5 \mathrm{~mL}$ aliquot of the upper layer was transferred to a polypropylene centrifuge tube containing $50 \mathrm{mg}$ PSA and $300 \mathrm{mg}$ anhydrous $\mathrm{MgSO}_{4}$. The tube was then vortexed for $0.5 \mathrm{~min}$ and centrifuged at $6000 \mathrm{rpm}$ for $5.0 \mathrm{~min}$.

After QuECHERS, $2 \mathrm{~mL}$ of the upper-layer acetonitrile extract (dispersive solvent) was transferred into a vial, $50 \mu \mathrm{L}$ of $\mathrm{C}_{6} \mathrm{H}_{5} \mathrm{Cl}$ (extractive solvent) was added into the vial. This mixture was rapidly transferred to $4 \mathrm{~mL}$ of water ( $\mathrm{pH}$ was adjusted to 3 with formic acid) in a conical centrifugation tube. The tube was closed and gently handshaken for $1 \mathrm{~min}$. Subsequently, it was centrifuged at $6000 \mathrm{r} / \mathrm{min}$ for $2 \mathrm{~min}$. The sedimented phase was completely transferred to another test tube with conical bottomusing $100 \mu \mathrm{L}$ HPLC syringe and then evaporated to dryness with a mild nitrogen stream. The residue was dissolved in $15.0 \mu \mathrm{L}$ of milli Q water $(0.1 \%$ formic acid) / acetonitrile (50:50, v/v) and injected into UPLC/MS/MS.

\subsection{Validation Study}

Validation of the optimized method was carried out following the 2002/657/EC decision. The analytical procedure was validated in terms of linear dynamic range, accuracy (recovery), precision (relative standard deviation, RSD) and selectivity.

Linearity was evaluated using matrix-matched calibration (MMC), spiking extracted blanks at five concentration levels between LOQ and $100 \mu \mathrm{g} / \mathrm{L}$. The accuracy and precision were assessed by fortification of water samples. Recovery and repeatability (intraday precision) was performed spiking blanks at three concentration levels $(0.2,2.0$ and $5.0 \mu \mathrm{g} / \mathrm{L})$, using six replicates for each concentration level in one day. To evaluate interday precision (reproducibility), the same concentration levels were studied, spiking blanks during six consecutive days.

\section{Results and Discussion}

The QuEChERS and DLLME combination was designed and applied to sample preparation of sulfonylurea herbicide from water samples. QuEChERS was applied as the first step and DLLME as the second step with extract obtained by the QuEChERS procedure used as the dispersive solvent for DLLME. The combination acts to enable a rapid and inexpensive sample pretreatment that not only results in a high enrichment factor, but is also applicable in complex matrices. Optimized UPLC-MS/MS analytical method was validated and used to determine selected sulfonylurea herbicide in water matrix.

\subsection{Optimization of the Analytical Method}

\subsubsection{Influence of the Sample Solution $\mathrm{pH}$}

$\mathrm{pH}$ value of the sample solution is a significant factor in extraction of selected sulfonylurea herbicides as it determines the state of analytes in solution as ionic or neutral molecules and also influences the stability of these herbicides. Sulfonylurea herbicides values ranging from 3.3 to 5.2 were evaluated to be more extractable at an acidic $\mathrm{pH}$ [20]. A pH level below 3 may work, however, to accelerate hydrolysis, particularly for TBM. The influence of sample $\mathrm{pH}$ was estimated in the $\mathrm{pH}$ range of $2.0 \sim 7.0$ as presented in Figure 2. Results demonstrate that recoveries of target compounds tended to increase as the $\mathrm{pH}$ value increased from $2.0-3.0$, but decreased when the $\mathrm{pH}$ value was increased above 3.0. The $\mathrm{pH}$ value of 3.0 was chosen as optimum $\mathrm{pH}$.

\subsubsection{Optimization of the Volumes of QuEChERS Extracts as the Dispersive Solvent}

Optimum volume of extract was evaluated for the QuEChERS procedure for use as a dispersive solvent for DLLME. Figure 3 demonstrates that highest recoveries were obtained by using $2 \mathrm{~mL}$ of the QuEChERS extract. Densities of the extractive solvent and the dispersive solvent change when using $3 \mathrm{~mL}$ of extract as increasing the volume of dispersive solvent more than $3 \mathrm{~mL}$ slightly decreases efficiency. Density of extractive solvent must be higher than that of water for DLLME [1]. 


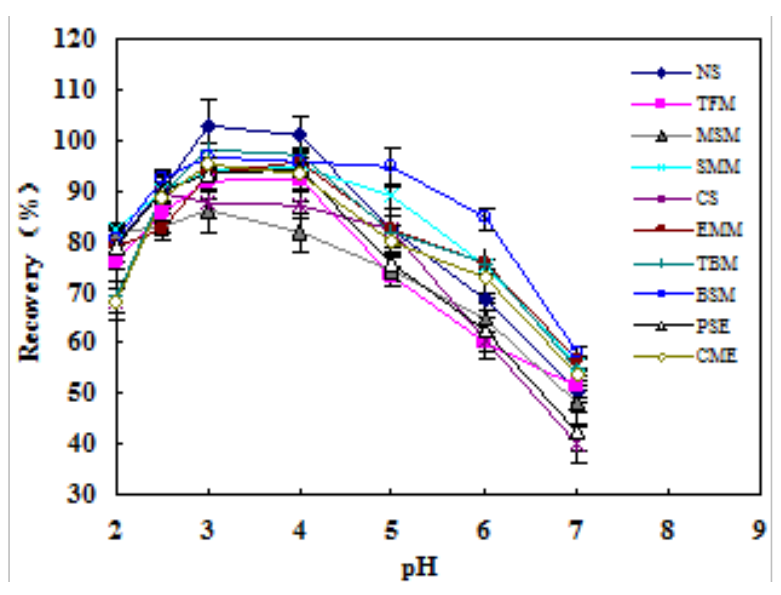

Figure 2. The effect of the sample solution $\mathrm{pH}$ on sulfonylurea herbicides recovery from QuEChERS for water sample at a concentration level of 2.0 $\mu \mathrm{g} / \mathrm{L}(\mathrm{n}=3)$.

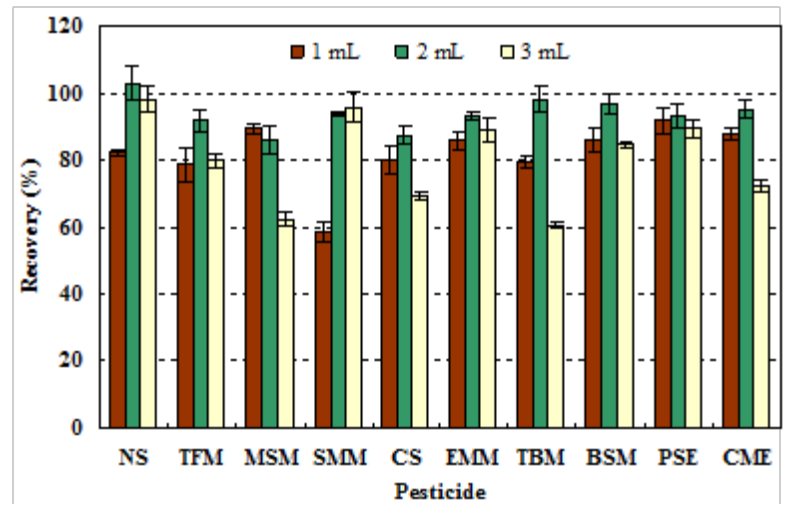

Figure 3. Comparison of recovery using different volumes of QuEChERS extracts as the dispersive solvent for DLLME for water sample at a concentration level of $2.0 \mu \mathrm{g} / \mathrm{L}(\mathrm{n}=3)$.

\subsubsection{Effect of the Kind and Volume of Extraction Solvent}

The selection of an appropriate extraction solvent is of great importance to the DLLME process. The extraction solvent should meet the following requirements: it should have a higher density than water, a low solubility in water, high extraction capability for the target analytes, and should form a stable two-phase system in the presence of a dispersive solvent when injected to an aqueous solution. Based on these criteria, $\mathrm{CHCl}_{3}, \mathrm{CH}_{2} \mathrm{Cl}_{2}, \mathrm{CS}_{2}$ and $\mathrm{C}_{6} \mathrm{H}_{5} \mathrm{Cl}$ were selected for the study. A comparison of recoveries utilizing different extractive solvents for water samples is presented in Figure 4. $\mathrm{C}_{6} \mathrm{H}_{5} \mathrm{Cl}$ gives the highest overall extraction efficiency for the target analytes among the four solvents investigated. Meanwhile, with $\mathrm{C}_{6} \mathrm{H}_{5} \mathrm{Cl}$ as extraction solvent, the use of acetonitrile as dispersive solvent could produce a two-phase system. Therefore, $\mathrm{C}_{6} \mathrm{H}_{5} \mathrm{Cl}$ was selected as the extraction solvent.

Extractive solvent volume was the next parameter studied with analytical responses for 10, 30, 50, 70 and $90.0 \mu \mathrm{L}$ of extractive solvent volume compared. Figure 5 shows the variation of extraction recovery versus volume of the extraction solvent. As the volume of $\mathrm{C}_{6} \mathrm{H}_{5} \mathrm{Cl}$ was increased, the extraction recovery was first increased until $50 \mu \mathrm{L}$, and then remained almost constant between 50 and $90 \mu \mathrm{L}$ for all the target analytes. From the obtained results, the extractive volume of $50 \mu \mathrm{L}$ was selected for further experimentation.

\subsection{Method Validation}

Evaluation of the method was conducted to evaluate several performance characteristics of the method, such as linearity, trueness, repeatability (intraday precision), reproducibility (interday precision), LODs, LOQs, CC $\alpha$, 


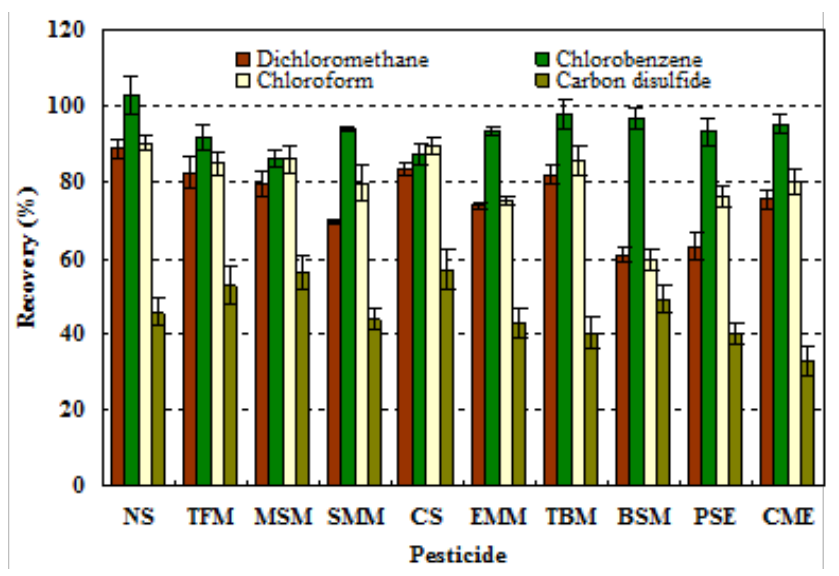

Figure 4. Comparison of recovery obtained with different extractive solvents trichloromethane for DLLME for water sample at a concentration level of $2.0 \mu \mathrm{g} / \mathrm{L}(\mathrm{n}=3)$.

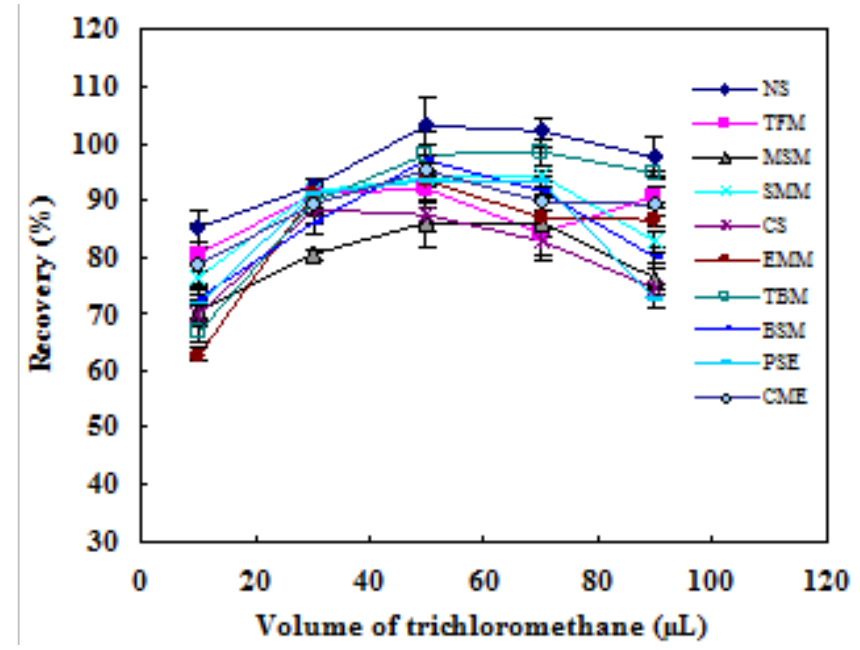

Figure 5. Comparison of recovery using different volumes of the extractive solvent $\mathrm{C} 6 \mathrm{H} 5 \mathrm{Cl}$ for DLLME for water sample at a concentration level of $2.0 \mu \mathrm{g} / \mathrm{L}(\mathrm{n}=3)$.

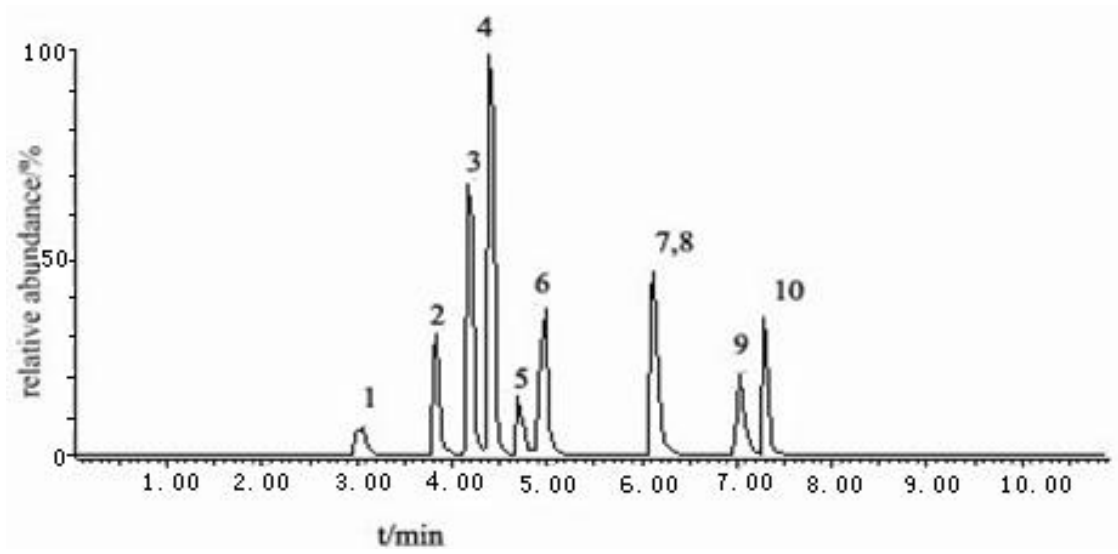

Figure 6. Chromatogram of $0.05 \mu \mathrm{g} \cdot \mathrm{L}^{-1}$ sulfonylurea herbicide working solution obtained in developed UPLC-MS/MS. 1: NS, 2: TFM, 3: MSM, 4: SMM, 5: CS, 6: EMM, 7: BSM, 8: PSE, 9: TBM, 10: CME. 
and $\mathrm{CC} \beta$. Slopes obtained in the calibration with the use of matrix-matched calibration (MMC) were compared to those obtained with solvent standards (SC) to evaluate the matrix effect. Matrix/solvent slope ratios (SSE) for each compound were then obtained (Table 2) with a signal enhancement or suppression effect considered acceptable if the slope ratio ranged from 0.8 to 1.2. Slope ratios higher values than 1.2 or lower than 0.8 indicate a strong matrix effect. A significant matrix effect was determined for the majority of the selected herbicides, whereas tolerable matrix effect was observed only for CS, BSM and CME.

Linearity was evaluated by MMC at the same ranges described above. Calibration curves were obtained by least-squares linear regression analysis of the peak area versus concentration. The calibration curves exhibited satisfactory linearity with determination coefficients (r2) higher than 0.997 in all the cases.

Trueness was estimated through recovery studies, applying the extraction procedure described previously. Table 3 displays satisfactory results for all assayed compounds at the three concentration levels, with recovery values between 81.2 and $109.1 \%$. Values of the procedure results met the European Commission requirements for validation recoveries indicating that a method may be considered accurate and precise when the accuracy of data is between $70 \%$ and $110 \%$, with relative standard deviations (RSDs) not higher than $20 \%$.

Table 2. Matrix effects SSE of QuEChERS-DLLME procedures calculated as slope ratio of MMC and SC for the herbicides.

\begin{tabular}{|c|c|c|c|c|c|}
\hline \multirow{2}{*}{ Herbicides } & \multicolumn{2}{|l|}{ MMC } & \multicolumn{2}{|l|}{ SC } & \multirow{2}{*}{$\begin{array}{l}\text { SSE } \\
\text { (i.e. slope } \\
\text { ratio) }\end{array}$} \\
\hline & $\begin{array}{l}\text { Linear equation for range } \\
\text { LOQ } \sim 100.0 \mu \mathrm{g} / \mathrm{L}\end{array}$ & $r^{2}$ & $\begin{array}{c}\text { Linear equation for range } \\
1.0 \sim 100.0 \mu \mathrm{g} / \mathrm{L}\end{array}$ & $r^{2}$ & \\
\hline NS & $y=108.56 x-80.12$ & 0.9978 & $y=150.86 x+97.48$ & 0.9991 & 0.72 \\
\hline TFM & $y=106.4 x-152.60$ & 0.9976 & $y=323.28 x+325.99$ & 0.9982 & 0.33 \\
\hline MSM & $y=69.3 x+43.23$ & 0.9997 & $y=194.2 x-300.44$ & 0.9970 & 0.36 \\
\hline SMM & $y=107.07 x-42.40$ & 0.9984 & $y=146.31 x-954.35$ & 0.9976 & 0.73 \\
\hline CS & $y=137.54 x+53.29$ & 0.9970 & $y=136.8 x-12.89$ & 0.9995 & 1.01 \\
\hline EMM & $y=137.75 x-122.56$ & 0.9995 & $y=631.84 x-416.53$ & 0.9995 & 0.22 \\
\hline TBM & $y=393.52 x-120.56$ & 0.9971 & $y=186.48 x+12.94$ & 0.9988 & 0.21 \\
\hline BSM & $y=313.98 x-79.97$ & 0.9975 & $y=363.68 x-112.53$ & 0.9994 & 0.86 \\
\hline PSE & $y=174.16 x-521.91$ & 0.9991 & $y=351.49 x+188.94$ & 0.9987 & 0.49 \\
\hline CME & $y=260.56 x+198.87$ & 0.9974 & $y=327.113 x+804.434$ & 0.9986 & 0.80 \\
\hline
\end{tabular}

Table 3. Recovery (\%), repeatability (RSDr, \%) and reproducibility (RSDR, \%) of the herbicides from spiked blank waters samples $(\mathrm{n}=6)$.

\begin{tabular}{cccccccccc}
\hline \multirow{2}{*}{ Herbicides } & \multicolumn{2}{c}{ Fortification level $0.2 \mu \mathrm{g} / \mathrm{L}$} & \multicolumn{2}{c}{ Fortification level $2.0 \mu \mathrm{g} / \mathrm{L}$} & \multicolumn{3}{c}{ Fortification level $5.0 \mu \mathrm{g} / \mathrm{L}$} \\
\cline { 2 - 10 } & $\begin{array}{c}\text { Mean } \\
(\%)\end{array}$ & $\begin{array}{c}\mathrm{RSD}_{\mathrm{r}} \\
(\%)\end{array}$ & $\begin{array}{c}\mathrm{RSD}_{\mathrm{R}} \\
(\%)\end{array}$ & $\begin{array}{c}\text { Mean } \\
(\%)\end{array}$ & $\begin{array}{c}\mathrm{RSD}_{\mathrm{r}} \\
(\%)\end{array}$ & $\begin{array}{c}\mathrm{RSD}_{\mathrm{R}} \\
(\%)\end{array}$ & $\begin{array}{c}\text { Mean } \\
(\%)\end{array}$ & $\begin{array}{c}\mathrm{RSD}_{\mathrm{r}} \\
(\%)\end{array}$ & $\begin{array}{c}\mathrm{RSD}_{\mathrm{R}} \\
(\%)\end{array}$ \\
\hline NS & 99.7 & 6.7 & 4.6 & 103.0 & 3.9 & 3.1 & 102.9 & 8.4 & 5.2 \\
TFM & 96.7 & 4.7 & 9.2 & 91.8 & 3.5 & 5.7 & 81.2 & 4.5 & 4.9 \\
MSM & 85.1 & 3.1 & 3.9 & 86.1 & 4.8 & 5.2 & 89.5 & 4.3 & 4.3 \\
SMM & 94.5 & 4.8 & 4.0 & 93.9 & 0.7 & 1.8 & 109.0 & 1.9 & 5.4 \\
CS & 90.9 & 2.4 & 6.2 & 87.5 & 3.2 & 2.5 & 104.9 & 6.4 & 3.7 \\
EMM & 87.7 & 2.4 & 7.9 & 93.5 & 1.3 & 5.4 & 96.5 & 3.6 & 2.6 \\
TBM & 91.3 & 4.4 & 5.2 & 98.1 & 4.0 & 5.2 & 86.2 & 3.7 & 3.3 \\
BSM & 89.7 & 4.0 & 4.6 & 96.9 & 2.9 & 4.4 & 104.6 & 1.0 & 5.3 \\
PSE & 86.9 & 4.5 & 3.8 & 93.2 & 3.6 & 6.1 & 109.1 & 8.2 & 3.4 \\
CME & 95.5 & 1.8 & 7.2 & 95.3 & 2.7 & 3.9 & 98.8 & 2.0 & 6.7 \\
\hline
\end{tabular}


Method precision was studied by performing repeatability (intraday precision) and reproducibility (interday precision) experiments. Intraday precision RSDr was measured by comparing recovery percentage standard deviations of spiked water samples run the same day. Interday precision RSDR was determined by analyzing spiked water samples for four alternate days. Replicated ( $\mathrm{n}=6$ for each concentration level) samples were then run and the RSD value was calculated for each herbicide. The method was found to be precise (RSD $<10 \%$ ) for all compounds studied at each spiking level (Table 3).

LODs and LOQs were calculated analyzing blank samples spiked at (1, 2, 5, 10, 20 and $30 \mu \mathrm{g} / \mathrm{L})$, and were determined as the lowest concentration of the analyte for which S/N were 3 and 10 respectively. The results displayed in Table 4 indicate that LODs and LOQs were consistently below $0.074 \mu \mathrm{g} / \mathrm{L}$ and $0.244 \mu \mathrm{g} / \mathrm{L}$, respectively.

The quality and correct interpretation of analytical results attained by control official laboratories are ensured by the Commission Decision 2002/657/EC. Two new parameters, decision limit CC $\alpha$ and detection capability $\mathrm{CC} \beta$, replace the former concepts, limit of detection and limit of quantitation. $\mathrm{CC} \alpha$ reflects the decision limit for sample non-compliance where error probability reaches $5 \%$ or above, whereas $C C \beta$ is the smallest content of the substance that may be detected, identified and/or quantified in a sample with an error probability of $\beta$. LOQs equal to or lower than the default maximum residue limits were established by European legislation at 0.01 $\mathrm{mg} / \mathrm{kg}$ thus, the CC $\alpha$ values were calculated by spiking 20 blank milk samples at the LOQ levels of the method for each herbicide. $\mathrm{CC} \alpha$ is represented by spiking level concentration plus 1.64 times the corresponding standard deviation. CC $\beta$ values were then calculated by analyzing 20 blank spiked samples at corresponding calculated $\mathrm{CC} \alpha$ levels for each analyte. Concentration of the $\mathrm{CC} \alpha$, plus 1.64 times the corresponding standard deviation, equals the CC $\beta$. Table 4 lists the obtained $\mathrm{CC} \alpha$ and $\mathrm{CC} \beta$ for the target compounds. The values ranged from 0.092 (EMM) to $0.252 \mu \mathrm{g} / \mathrm{L}$ (NS) for CC $\alpha$ and from 0.101 (PSE) to 0.260 (NS) $\mu \mathrm{g} / \mathrm{L}$ for CC $\beta$.

\section{Real water Sample Analysis}

The validation method was applied to determine sulfonylurea herbicides residue levels in 42 water samples obtained from the eastern Tiaoxi River in Hangzhou (China) in 2011 with all water samples analyzed in duplicate. Purpose of the analyses was to examine levels of sulfonylurea herbicides residues in typical rice-production areas and to investigate its risk to aquatic weeds.

Only three of the analytes, TFM, MSM, and CME, were discovered in the 42 water samples, with only TFM detected above the LOQ in three samples at $0.17-0.20 \mu \mathrm{g} / \mathrm{L}$. Concentrations of TFM in above three samples exceeding the baseline concentration for non-target aquatic plant toxicity $\left(100 \mathrm{ng} \cdot \mathrm{L}^{-1}\right)$, implying potential toxic stress to flora in the streams [4]. The analyses further revealed traces of TFM in three samples, MSM in five samples and CME in six samples (Table 5). No other sulfonylurea herbicides residues were observed in these water samples. The occurrence of TFM in the eastern Tiaoxi River, according to research

Table 4. LODs and LOQs values and calculations of decision limits (CC $\alpha)$ and $(\mathrm{CC} \beta)$ at the LOQ levels ofthe method.

\begin{tabular}{|c|c|c|c|c|c|c|}
\hline Herbicides & $\begin{array}{c}\mathrm{LOD} \\
(\mu \mathrm{g} / \mathrm{L})\end{array}$ & $\begin{array}{c}\mathrm{LOQ} \\
(\mu \mathrm{g} / \mathrm{L})\end{array}$ & $\begin{array}{c}\text { Measured } \pm \text { SD } \\
(\mu \mathrm{g} / \mathrm{L})\end{array}$ & $\begin{array}{c}\mathrm{CC}_{\alpha} \\
(\mu \mathrm{g} / \mathrm{L})\end{array}$ & $\begin{array}{c}\text { Measured } \pm \text { SD } \\
(\mu \mathrm{g} / \mathrm{L})\end{array}$ & $\begin{array}{c}\mathrm{CC}_{\beta} \\
(\mu \mathrm{g} / \mathrm{L})\end{array}$ \\
\hline NS & 0.074 & 0.244 & $0.241 \pm 0.005$ & 0.252 & $0.243 \pm 0.008$ & 0.260 \\
\hline TFM & 0.047 & 0.155 & $0.140 \pm 0.012$ & 0.175 & $0.150 \pm 0.006$ & 0.181 \\
\hline MSM & 0.044 & 0.145 & $0.140 \pm 0.006$ & 0.155 & $0.142 \pm 0.004$ & 0.159 \\
\hline SMM & 0.051 & 0.168 & $0.152 \pm 0.009$ & 0.183 & $0.155 \pm 0.010$ & 0.193 \\
\hline CS & 0.048 & 0.158 & $0.146 \pm 0.014$ & 0.181 & $0.150 \pm 0.009$ & 0.190 \\
\hline EMM & 0.025 & 0.082 & $0.070 \pm 0.006$ & 0.092 & $0.080 \pm 0.010$ & 0.102 \\
\hline TBM & 0.037 & 0.122 & $0.098 \pm 0.009$ & 0.137 & $0.114 \pm 0.011$ & 0.148 \\
\hline BSM & 0.043 & 0.142 & $0.130 \pm 0.013$ & 0.163 & $0.135 \pm 0.007$ & 0.170 \\
\hline PSE & 0.027 & 0.089 & $0.075 \pm 0.004$ & 0.096 & $0.082 \pm 0.005$ & 0.101 \\
\hline CME & 0.048 & 0.158 & $0.143 \pm 0.011$ & 0.176 & $0.149 \pm 0.012$ & 0.188 \\
\hline
\end{tabular}


Table 5. Average concentration $(\mu \mathrm{g} / \mathrm{L})$ of sulfuronylurea herbicides found in real water samples (means of duplicate analyses).

\begin{tabular}{|c|c|c|c|c|c|c|c|}
\hline Substance & 1 & 2 & 3 & 4 & 5 & 6 & 7 \\
\hline NS & $<\mathrm{LOD}$ & $<\mathrm{LOD}$ & $<$ LOD & $<\mathrm{LOD}$ & $<$ LOD & $<\mathrm{LOD}$ & $<\mathrm{LOD}$ \\
\hline TFM & detectable & 0.20 & 0.20 & detectable & 0.17 & detectable & $<\mathrm{LOD}$ \\
\hline MSM & detectable & detectable & detectable & detectable & detectable & $<\mathrm{LOD}$ & $<\mathrm{LOD}$ \\
\hline SMM & $<\mathrm{LOD}$ & $<\mathrm{LOD}$ & $<\mathrm{LOD}$ & $<\mathrm{LOD}$ & $<\mathrm{LOD}$ & $<\mathrm{LOD}$ & $<\mathrm{LOD}$ \\
\hline CS & $<\mathrm{LOD}$ & $<\mathrm{LOD}$ & $<\mathrm{LOD}$ & $<$ LOD & $<\mathrm{LOD}$ & $<\mathrm{LOD}$ & $<\mathrm{LOD}$ \\
\hline EMM & $<\mathrm{LOD}$ & $<\mathrm{LOD}$ & $<\mathrm{LOD}$ & $<\mathrm{LOD}$ & $<\mathrm{LOD}$ & $<\mathrm{LOD}$ & $<\mathrm{LOD}$ \\
\hline TBM & $<$ LOD & $<$ LOD & $<\mathrm{LOD}$ & $<\mathrm{LOD}$ & $<\mathrm{LOD}$ & $<\mathrm{LOD}$ & $<\mathrm{LOD}$ \\
\hline BSM & $<\mathrm{LOD}$ & $<\mathrm{LOD}$ & $<\mathrm{LOD}$ & $<\mathrm{LOD}$ & $<\mathrm{LOD}$ & $<\mathrm{LOD}$ & $<\mathrm{LOD}$ \\
\hline PSE & $<\mathrm{LOD}$ & $<\mathrm{LOD}$ & $<$ LOD & $<\mathrm{LOD}$ & $<\mathrm{LOD}$ & $<\mathrm{LOD}$ & $<\mathrm{LOD}$ \\
\hline CME & detectable & detectable & detectable & detectable & detectable & detectable & $<\mathrm{LOD}$ \\
\hline
\end{tabular}

results, is above acceptable levels and the risk to aquatic organisms is significant.

\section{Conclusions}

In this paper, QuEChERS clean-up combined with DLLME has been developed as a new approach for the extraction of sulfonylurea herbicides in water sample prior to UPLC/MS/MS measurement. The combination of QuEChERS-DLLME makes it possible that selective determination of the trace analytes in complex matrices can be easily carried out. Compared with other conventional sample preparation methods, the analytical technique offers advantages such as simplicity, ease of operation, relatively short analysis time, and lower consumption of organic solvent. The developed QuEChERS-DLLME with UPLC-MS/MS method for the analysis of sulfonylurea herbicides residues in water samples is a useful tool for the monitoring of water samples for these substances. The exploration of the QuEChERS-DLLME with UPLC-MS/MS method for the extraction of other pesticides and contaminants in various complex matrix samples is currently underway in our lab. Meanwhile, the results of real samples indicated 17 samples and 3 of herbicides were discovered and, most importantly, TFM residue levels were revealed to exceed established levels of acceptance. These results from this study would provide data necessary to assess whether these herbicides occurred in surface waters to exert detrimental effects on non-target aquatic organisms.

\section{Acknowledgements}

This study was financially supported by the National Natural Science Foundation of China (No. 41101307) and the Central Public Scientific Research Institutions Basal Research Fund Special Funds (20160210).

\section{References}

[1] Gure, A., Lara, F.J., Moreno-González, D., Megersa, N., del Olmo-Iruela, M. and García-Campaña, A.M. (2014) Salting-Out Assisted Liquid-Liquid Extraction Combined with Capillary HPLC for the Determination of Sulfonylurea Herbicides in Environmental Water and Banana Juice Samples. Talanta, 127, 51-58. http://dx.doi.org/10.1016/j.talanta.2014.03.070

[2] Yan, C., Zhang, B., Liu, W., Feng, F., Zhao, Y. and Du, H. (2011) Rapid Determination of Sixteen Sulfonylurea Herbicides in Surface Water by Solid Phase Extraction Cleanup and Ultra-High-Pressure Liquid Chromatography Coupled with Tandem Mass Spectrometry. J Chromatogr B, 879, 3484-3489. http://dx.doi.org/10.1016/j.jchromb.2011.09.028

[3] Jenny, K. and Stina, A. (2008) Monitoring of Sulfonylurea Herbicides in Stream Water Draining Intensively Cultivated Areas in Southern Sweden during a 9-Year Period (1998-2006). http://pub.epsilon.slu.se/5401/1/kreuger_j_et_al_101101.pdf

[4] De Lafontaine, Y., Beauvais, C., Cessna, A.J., Gagnon, P., Hudon, C. and Poissant, L. (2014) Sulfonylurea Herbicides in an Agricultural Catchment Basin and Its Adjacent Wetland in the St. Lawrence River Basin. Sci Total Environ, 479-480, 1-10. http://dx.doi.org/10.1016/j.scitotenv.2014.01.094 
[5] Zhou, Q.X., Liu, J.F., Cai, Y.Q., Liu, G.G. and Jiang, G.B. (2003) Micro-Porous Membrane Liquid-Liquid Extraction as an Enrichment Step Prior to Nonaqueous Capillary Electrophoresis Determination of Sulfonylurea Herbicides. Microchem J, 74, 157-163. http://dx.doi.org/10.1016/S0026-265X(03)00003-1

[6] Ayano, E., Kanazawa, H., Ando, M. and Nishimura, T. (2004) Determination and Quantitation of Sulfonylurea and Urea Herbicides in Water Samples Using Liquid Chromatography with Electrospray Ionization Mass Spectrometric Detection. Anal Chim Acta, 507, 211-218. http://dx.doi.org/10.1016/j.aca.2003.11.027

[7] Losito, I., Amorisco, A., Carbonara, T., Lofiego, S. and Palmisano, F. (2006) Simultaneous Determination of Phenyland Sulfonyl-Urea Herbicides in River Water at Sub-Parts-per-Billion Level by On-Line Preconcentration and Liquid Chromatography-Tandem Mass Spectrometry. Anal Chim Acta, 575, 89-96. http://dx.doi.org/10.1016/j.aca.2006.05.063

[8] Degelmann, P., Egger, S., Jürling, H., Müller, J., Niessner, R. and Knopp, D. (2006) Determination of Sulfonylurea Herbicides in Water and Food Samples Using Sol-Gel Glass-Based Immunoaffinity Extraction and Liquid Chromatography-Ultraviolet/Diode Array Detection or Liquid Chromatography-Tandem Mass Spectrometry. Food Chem, 54, 2003-2011. http://dx.doi.org/10.1021/jf052718+

[9] Liu, J.F., Chao, J.B., Jiang, G.B., Cai, Y.Q. and Liu, J.M. (2003) Trace Analysis of Sulfonylurea Herbicides in Water by On-Line Continuous Flow Liquid Membrane Extraction-C18 Precolumn Liquid Chromatography with Ultraviolet Absorbance Detection. J Chromatogr A, 995, 21-28. http://dx.doi.org/10.1016/S0021-9673(03)00515-6

[10] Penmetsa, K.V., Leidy, R.B. and Shea, D. (1997) Enantiomeric and Isomeric Separation of Herbicides Using Cyclodextrin-Modified Capillary Zone Electrophoresis. J Chromatography A, 790, 225-234. http://dx.doi.org/10.1016/S0021-9673(97)00765-6

[11] Anastassiades, M., Lehotay, S.J., Štajnbaher, D. and Schenck, F.J. (2003) Fast and Easy Multiresidue Method Employing Acetonitrile Extraction/Partitioning and "Dispersive Solid-Phase Extraction" for the Determination of Pesticide Residues in Produce. J AOAC Int, 86, 412-431.

[12] Mastovska, K. and Lehotay, S.J. (2006) Rapid Sample Preparation Method for LC-MS/MS or GC-MS Analysis of Acrylamide in Various Food Matrices. J Agr Food Chem, 54, 7001-7008. http://dx.doi.org/10.1021/jf061330r

[13] Seccia, S., Albrizio, S., Fidente, P. and Montesano, D. (2011) Development and Validation of a Solid-Phase Extraction Method Coupled to High-Performance Liquid Chromatography with Ultraviolet-Diode Array Detection for the Determination of Sulfonylurea Herbicide Residues in Bovine Milk Samples. J Chromatogr A, 1218, 1253-1259. http://dx.doi.org/10.1016/j.chroma.2011.01.006

[14] Zhao, P., Wang, L., Zhou, L., Zhang, F., Kang, S. and Pan, C. (2012) Multi-Walled Carbon Nanotubes as Alternative Reversed-Dispersive Solid Phase Extraction Materials in Pesticide Multi-Residue Analysis with QuEChERS Method. $J$ Chromatogr A, 1225, 17-25. http://dx.doi.org/10.1016/j.chroma.2011.12.070

[15] Lehotay, S.J., Son, K.A., Kwon, H., Koesukwiwat, U., Fud, W., Mastovska, K., Hoha, E. and Leepipatpiboonc, N. (2010) Comparison of QuEChERS Sample Preparation Methods for the Analysis of Pesticide Residues in Fruits and Vegetables. J Chromatogr A, 1217, 2548-2560. http://dx.doi.org/10.1016/j.chroma.2010.01.044

[16] Cunha, S.C. and Fernandes, J.O. (2011) Multipesticide Residue Analysis in Maize Combining Acetonitrile-Based Extraction with Dispersive Liquid-Liquid Microextraction Followed by Gas Chromatography-Mass Spectrometry. $J$ Chromatogr A, 1218, 7748-7757. http://dx.doi.org/10.1016/j.chroma.2011.08.066

[17] Rezaee, M., Assadi, Y., Hosseini, M.R.M., Aghaee, E., Ahmadi, F. and Berijani, S. (2006) Determination of Organic Compounds in Water Using Dispersive Liquid-Liquid Microextraction. J Chromatogr A, 1116, 1-9. http://dx.doi.org/10.1016/j.chroma.2006.03.007

[18] Wu, Q., Wang, C., Liu, Z., Wu, C., Zeng, X., Wen, J. and Wang, Z. (2009) Dispersive Solid-Phase Extraction Followed by Dispersive Liquid-Liquid Microextraction for the Determination of Some Sulfonylurea Herbicides in Soil by High-Performance Liquid Chromatography. J Chromatogr A, 1216, 5504-5510.

http://dx.doi.org/10.1016/j.chroma.2009.05.062

[19] Caldas, S.S., Costa, F.P. and Primel, E.G. (2010) Validation of Method for Determination of Different Classes of Pesticides in Aqueous Samples by Dispersive Liquid-Liquid Microextraction with Liquid Chromatography-Tandem Mass Spectrometric Detection. Anal Chim Acta, 665, 55-62. http://dx.doi.org/10.1016/j.aca.2010.03.004

[20] Sui, K., Li, J., Wei, F., Chu, X., Zhao, S. and Wang, Y. (2006) Simultaneous Determination of Twelve Sulfonyl Urea Herbicide Residues in Rice by High Performance Liquid Chromatography with Solid-Phase Extraction. Chin J Chromatogr, 24, 152-156. 